Journal of Teacher Education for Sustainability, vol. 23, no. 1, pp. 69-83, 2021

\title{
Implementing a Spiritual and Moral Education Program for Maths Teachers
}

\author{
Yevgeniya Gerasimova, Svetlana Dvoryatkina, \\ Olga Savvina and Sergey Shcherbatykh \\ Bunin Yelets State University, Yelets, Russian Federation
}

\begin{abstract}
Modern researchers focus on spiritual and moral education only of children, particularly in the humanities. In this study, we develop and implement a program for the spiritual and moral education of 24 mathematics teachers aged between 30 and 65 years and assess its effectiveness. The program's effectiveness was assessed based on previously developed psychodiagnostic tools by expanding spiritual and moral development characteristics with new components. Diagnostics of the primary state of personal characteristics of spirituality was conducted before the experimental training and after implementing the program. We analyzed data using the Wilcoxon T-test, which revealed a significant increase in value-semantic, communicative, reflexive, motivational, and critical parameters. A qualitative analysis was conducted by evaluating the further research activities of $60 \%$ of the students. Our program can be used in postgraduate education in a wide range of specialties and areas of training worldwide. The program can provide advanced training in solving spiritual and moral education issues for mathematics teachers.
\end{abstract}

Key words: spiritual education, moral education, spirituality, educators' advanced training - mathematicians

\section{Introduction}

Cultural and moral education of young people is one of the challenging tasks in education, especially given the digital economy and transformation of education in modern society where spiritual and moral values are questioned and overestimated. Thus, there is a growing need to strengthen the pedagogy to develop traditional education and find new methods to educate youth to a higher quality level. The need to solve the triune task of educating a highly moral, cultured, professional teacher who is a bearer of higher spiritual values exacerbates the challenges in higher education. As the ancients aptly noted in Latin, the verba movent, exempla trabunt. To develop a thinking, compassionate, and aspiring student, the teacher must possess these qualities.

According to Russian teachers and philosophers (N. I. Pirogov, K. D. Ushinsky, N. A. Berdyaev, G. A. Ilyin), professional training of a teacher is impossible without spiritual and moral education, without familiarizing with spiritual and moral values - 
service to duty, truth, beauty, love for one's neighbor, and the fatherland. These ideas serve as methodological guidelines for the organization of the educational process aimed at the education and development of the spiritual and moral sphere of the teacher's personality.

With the modern development of mutual relations between countries, spiritual and moral education of youth has been the subject of many scholars (Carpenter, 2020; Pandya, 2020; Sardoč, 2019; Shirshov, 2020; Tokic, 2019). However, the spiritual and moral education of teachers' personalities has not been explored adequately.

The dominant attitudes of the education system at higher educational institutions in Russia have traditionally focused on the formation of personal culture, the enrichment of its spiritual and moral values, and the formation of a holistic vision of nature, society, and humanity (sample program "philosophy"; sample discipline program "history"). At the same time, it is believed that students' spiritual and moral education is the domain of humanities (Bahchieva, 2017; Belkin et al., 2015, 2016; Bazarova, 2019; Shirshov, 2020; Korolkov, 2006). However, natural and mathematical disciplines have significant potential to complement and enrich this process with their methods, techniques, and tools (Dvoryatkina et al., 2018; Halstead, 1994; Ptitsyn, 2019; Savvina \& Melnikov, 2019; Moulin-Stożek, 2020). Using such qualities of mathematics as the universal language and methods, beauty in aesthetic content, and in relation to the laws of nature, technical, economic, natural and humanitarian sciences, music, painting, architecture, and art can serve as the fundamentals of the individual with value-semantic guidelines and enrichment with spiritual and moral values.

Mathematics can help achieve spiritual and moral education. First, it equips teachers with skills to plan activities, develop and make optimal decisions, test actions, and distinguish between reasoned and unsubstantiated statements. Second, solving mathematical problems leads to a systematic tension of mental effort, perseverance in overcoming difficulties, the ability to focus, and character traits such as diligence, perseverance, and determination.

Mathematics teaches use to love the truth and seek it. Compared with humanities, mathematics has clarity, and so it is the demand where there is a desire for truth. Studying mathematics shapes logical thinking, including analysing, synthesis, generalization, connecting judgements, correctly establishing syllogisms, and building inferences.

The axiomatic method introduces certainty, making it easier to see an error and rule out lies. It allows seeing the world not as a random combination of elements moving towards destruction but as a testimony of God, who wisely arranged everything. Mathematical formulas, models, and dependencies illustrate the beauty of the world around and cultivate an aesthetic taste. Therefore, this aspect of the problem of spiritual and moral education and formation requires further study.

The importance of spiritual and moral education has also been recognized at the national level. On 22 February 2018, Russia adopted new federal state educational standards. The Bachelor study program 44.03.05 "Pedagogical Education" comprises professional competencies "Building an Educative Environment". In turn, these competencies include the following general professional competence: "the ability to provide spiritual and moral education of students based on basic national values (GPC-4)" (Federal State Educational Standard). Since this competence was not present in previous educational programs of higher education institutions and modern standards, developing new approaches to postgraduate vocational education focused on the spiritual and moral 
formation and development of practicing teachers. Therefore, spiritual and moral education should be of paramount importance in advanced training programs for educators.

The research problem of the study is as follows: What are the theoretical and methodological approaches and didactic mechanisms of modernisation of postgraduate professional education, focusing on the spiritual and moral formation and development of mathematics teachers? The study aims to develop and implement a program for the spiritual and moral education of teachers and evaluate its effectiveness in mathematics teachers.

\section{Literature Review}

Understanding spiritual and moral education as dominating factors in the professional development of modern educators requires a systematic analysis of the relevant literature. In pedagogical research, there is a tradition of separating religious and secular (scientific and "religiously untethered" - T. H. (McLaughlin, 2003)) spirituality.

Researchers often focus on spirituality in the context of "religious commitment" and mostly in secondary schools (McLaughlin, 2003; Benson, 2004; Wintersgill, 2008). These approaches assume aspiration for perfection. The religious approach to the definition of spirituality is found in Slobodchikov's work. He writes, "Spirituality, also in its most general form, is the cause and effect of faith in a higher, super-ordinary principle in human life" (Slobodchikov, 2010, p. 92).

The most common secular concept of understanding spirituality is perceived as a socio-cultural phenomenon (Chiang Yi-Chien, 2020; Carr, 1996; Pandya, 2020). "The ability to express, preserve, and create culture is a specific human attribute, which is attributed to the spiritual realm. This means that spiritual education can be fulfilled only within culture, by including the learner in the cultural characteristic of the society in which he lives" (Nalyotova 1999, p. 72). Buyeva (2005), Valiakhmetov (2002), and other scholars associate spirituality with the production of meaning and meaning-making. In Buyeva's opinion, spirituality is a problem of acquiring meaning as well as an indicator of a certain hierarchy of values, goals, and meanings (Buyeva, n.d.). Therefore, one of the most important characteristics of spirituality is its value and meaningful character. In this case, spiritual education is regarded as a process of fundamental value and meaning orientation, associated with the acquisition of spiritual and moral experience and the need to create conditions for the spiritual formation and development of personality (Solovtsova, 2012; Pandya, 2020). Khugaeva (2019) highlights the dialogical nature of spirituality, which implies the possibility of comprehending both spiritual and inner world of other people and culture as a whole.

Thus, spirituality can be defined as a personal trait that ensures, on the one hand, the stability of one's meaningful life attitude (secular understanding) and, on the other hand, the perspective of personal development (religious aspect).

Spiritual and moral education are intercultural phenomena. The problem of spiritual and moral education has been the focus of modern scientists from different countries: Croatia (Tokic, 2019), China (Kaili, 2012), Britain (Rodger, 2000; Rossiter, 2006; Moulin-Stożek, 2020), Russia (Menshikov \& Khokhlova, 2018), and Slovenia (Sardoč, 2019).

Benson (2004), Carr (1995, 1996), and Wintersgill (2008) have contributed to addressing the spiritual development of adolescents in school, making a reasonable 
comparison between religious and spiritual development. Bigger et al. (2013) explored spiritual values in the curriculum and provided an introductory platform, consistently pointing to sources of further reading. "The promotion of creative moral and spiritual education requires that there be shared values within a school" (Wilson, 1993, p. 5). Deakin and Jelfs (2011) noted that the formulation and solution to the most problems of the spiritual and religious development of students determine the perspective and general recognition of this field of research in the development of a nation's spiritual potential and spiritual well-being.

In contrast to Britain and other Western countries, where spiritual and moral development tends to be incorporated into general education through diverse approaches (Rossiter, 2006), Russia incorporates spiritual and moral education in the humanities and social sciences (Belkin et al., 2015, 2016; Bazarova, 2019; Shirshov, 2020; Korolkov, 2006).

As Troitsky aptly notes, "the Russian school is an organic part of Russian civilisation, with the spiritual and moral criterion as its formative beginning basis. It grew out of the Orthodox Christian view of the essence of being, out of the Orthodox faith, which brings up the divine beauty of the human soul that is embodied both in Russian literature and art" (Troitsky, 2010, p. 14).

Curren (2014) and Szutta (2019) confirmed the ambivalence and an extremely high degree of difficulty in solving spiritual and moral education and the development of criteria for its solution. Watson (2019) focused on intellectual character education and drew attention to an interesting case in which exemplarism in the classroom might inhibit, rather than promote, the development of intellectually virtuous character.

Bahchieva (2017), Croce (2019), and Ptitsyn (2019) propose simple ways of spiritual and moral education. Ptitsyn's (2019) research is devoted to implementing a holistic approach to the study of computer science through spiritual education on the example of computer modelling of folk patterns. Tisdale (2014) noted that psychology is of great importance in spiritual education.

Menshikov and Khokhlova (2018) set the following requirements for the professional training of an educator who provides spiritual and moral education: spiritual and moral growth, love for children and the subject, high professionalism and constant self-improvement, and understanding of the virtue and responsibility of one's duties. Carpenter (2020) believed that teachers teached their values.

The mechanisms for implementing spiritual and moral education are based on dialogical principles. This principle is the basis for creating conditions for spiritual education in the context of the joint activities of educators and students (Solovtsova, 2012). The dialogical principle helps identify and establish the contradictions between spiritual education and its different sides' internal unity.

Another theoretical and methodological basis is the principle of search and research for something that is not new but eternal. The principle of love (the teacher's love toward their children and their love for the subject) is considered an eternal parameter.

"To be successful in school, one needs to love what one wants to know. However, the less you know, the less love you love. True knowledge increases the possibility of love. Love ignites thirst for knowledge and expands it. Thus, the indispensable task of training must be the education of love for knowledge" (Troitsky, 2010, p. 11). 
Ostapenko and Khagurov (2011) saw the key role of education in providing a child with a right attitude toward knowledge, activity, and other people.

"And the right attitude is love... If we manage to cultivate it, then a graduate develops love for knowledge (curiosity), love for activity (hard work), love for people (kindness), and for life (cheerfulness). If love in education runs out, then an efficient and competitive economist develops perfect corruption schemes, while a competent lawyer works for the mafia..." (Khagurov \& Ostapenko, 2011, p. 27).

Thus, the interest of modern educators in improving their knowledge, fostering spiritual and moral culture, and showing interest in the scientific knowledge of students can be considered qualitative criteria for assessing the success of spiritual and moral education. There has been very little research on adult spiritual education. Researchers have shown a positive impact of spiritual education for caregivers (Moghaddam et al., 2016) and nurses (Chiang et al., 2020). The experience of the South Asian senior spiritual education program is described in Pandya (2020). The author does not indicate that he set Christian goals in the program (love for God and neighbor), but believes that this program had a positive impact on self-efficacy and prosocial behavior.

Thus, love for children and the subject, mindfulness, and responsibility, the need for self-development, and the desire for self-improvement are the main indicators of the level of spiritual development of the educator's personality.

\section{Materials and Methods}

\section{Curriculum}

Training and retraining teachers to effectively solve pedagogical problems of spiritual and moral development by means of mathematics require an innovative approach. This study develops mechanisms for organizing and determining scientific and methodological content for maths teachers to provide spiritual and moral educational services. This innovative spiritual development project includes the following steps:

- Preparatory and organizational: improving psychodiagnostic tools for analyzing and evaluating the level of spiritual and moral development; identifying the level of formation of personal qualities and abilities that express the spiritual and moral development of teachers before the introduction of a new program of additional professional education.

- Formative: developing and implementing the program "Modern Mathematical Training in Spiritual and Moral Education Following the Federal State Educational Standard (FSES) Implementation".

- Estimated: evaluating the effectiveness of this program by changing the level of formation of personal qualities and abilities that express the spiritual and moral development of teachers, and conducting a qualitative assessment of the effectiveness and efficiency of the program, based on the research activities of teachers in theory and practice of spiritual and moral education, and the involvement of students in this type of activity. 


\section{Participant (Subject) Characteristics}

Participants of professional development programs were students who already had both life and pedagogical experiences. These were adults with a well-established worldview; thus, we included worldview in the program. Since it is hard to imagine spirituality without the involvement of a religious worldview, the program should include the study of primary sources, including the Holy Scripture. Twenty-four students from different regions were enrolled in the program "Modern Mathematical Training in Spiritual and Moral Education Following FSES Implementation” with prior consent from them. The average age of the participants was 47 years ( $\mathrm{SD}=9$ years). The age of the participants ranged from 30 to 64 years (range, $\mathrm{R}=34$ ). Age was non-normally distributed, with skewness of 0.4 , and kurtosis of 0.53 . The scientific qualifications of the students were relatively high. There were 15 candidates of science (three candidates of physical and mathematical sciences, one candidate of economic sciences, and 11 candidates of pedagogical sciences). There were also four Doctors of Sciences, four secondary school teachers, and one teacher of higher school without an academic degree.

\section{Procedure}

The development of the program curriculum was carried out by the Interregional Educational Public Organisation team, Association of Orthodox Christian Academic Specialists, and the lecturers of the Department of Mathematics and Methods of Teaching.

Within the framework of professional development, a program of spiritual and moral education "Modern Mathematical Training in Spiritual and Moral Education Following FSES Implementation" was developed and implemented.

The program's announcement was posted on the websites of the Department of Mathematics and Methods of Teaching and of the Association of Orthodox Christian Academic Specialists. Documentary and material support (orders, classrooms, equipment, etc.) were provided by Yelets University. The volume of the program is 72 hours: 40 hours in a full-time mode, and 32 hours in a part-time mode.

The program includes two modules:

1. Universal module. This module deals with creating pedagogical conditions for the development of students at higher, secondary vocational, and general education programs.

2. Special module. This module deals with the methodological aspects of spiritual and moral development of personality in mathematics education.

Module 1: It includes the following topics:

- State education policy in the Russian Federation. The themes include regulatory and legal support for the implementation of the state policy in spiritual and moral education, history of relations between the Church and the state, cooperation between the Church and the state in modern conditions, a higher school in a multicultural environment, cultural identity, and principles of development of spiritual and moral education in the Russian Federation.

- Spiritual foundations of national culture. The themes include religious and philosophical foundations of culture, culture, and civilisation, anthropological foundations of culture and education, culturally appropriate types of education, the Bible in modern culture, and the Holy Scripture and its significance for national pedagogy. 
This module does not reflect the specifics of the subject taught by the educator; therefore, it is universal.

Module 2: This is the special module; it addresses the following issues:

- Psychological and pedagogical fundamentals of spiritual and moral development in mathematics education;

- Age peculiarities of spiritual and moral development;

- Education as a process;

- The role of spiritual and moral education in the educational process of spiritual and moral components of professional and pedagogical activities;

- Potential of mathematics education for national security;

- Mathematics education and morality (mathematics as part of universal culture);

- Modern stage of the development of mathematics;

- Worldview of mathematicians and their influence on mathematical creativity and pedagogical activity;

- Methodological problems of modern mathematical education (real and imaginary threats to modern mathematics education);

- Signs of the crisis in the domestic methodology of teaching mathematics;

- Traditions of Russian mathematics education;

- Metaphysical approach to mathematics education;

- Methodological features of the implementation of spiritual and moral components in mathematics education (the concept of spiritual and moral development and education of the individual citizen of the Russian Federation);

- Brief description of educational methods and technologies used in modern pedagogical practice.

Since the latter theme reflects the specifics of educational aspects of mathematics education, let us consider it in detail:

Moral, philosophical and worldview issues were included in the curriculum of the program. Teaching is based on the dialogue principle. The students were informed about a curious historical phenomenon: the study of regularities in random phenomena was conducted by mathematicians (the founders of probability theory), most of whom were believers. The first person who raised the question of studying random phenomena was Wibold, the bishop of Cambrai, who invented the game "Ludus Clericalis" and was invited to reflect on what Wibold's fallacy was. In this lecture, an analysis of the factors that led to the Schism of 1054 will also be relevant.

Divine love is a fundamental and essential concept of Christianity. It is inextricably linked to the basic principle of God, the Creator, the principle of freedom. God created everything with His own free will. How mathematical scholars exercise this "will" was illustrated by specific topics covered in the program: The spiritual evolution of Luca Pacioli, Binary views of Girolamo Cardano, Pascal's God and the birth of the probability theory, Bernoulli's reasonable faith, The facets of interaction between science and religion by Thomas Bayes.

There is no doubt that only a loving heart can teach love, so a mathematics educator must be guided by love for children and their discipline.

The implementation of the program involved various stakeholders such as the lecturers and priests. Priests participated in implementing the module "Creating Pedagogical Conditions for the Development of Students at Higher, Secondary Vocational and General Education Programs". 
To achieve spiritual and moral education, students and lecturers should cooperate and have good communication in an informal setting. Thus, at the end of the program, lecturers and students visited various holy places of Lebediansky district.

\section{Evaluation}

To identify the dynamics of the level of formation of the qualities and abilities of the personality, we modernised the spiritual and moral development of the personality and the psychodiagnostic tools (Dvoryatkina et al., 2018). The selected criteria for the manifestation of spiritual and moral development (value-semantic, communicative, reflexive) were expanded with motivational and critical components. The motivational component was diagnosed using the Rean questionnaire "Motivation for Success and Fear of Failure" (Rean, 2006), and the critical component was diagnosed using the Stark critical thinking test (Starkey, 2004).

The Rean test questionnaire is a classic psychological method for diagnosing the prevailing type of motivation: motivation for success or fear of failure. Success motivation refers to positive motivation, in which a person's actions aim to achieve constructive positive results. Individuals of this type are usually active and proactive. If there are obstacles, they look for ways to overcome them. They are distinguished by their perseverance in achieving their goals. The motivation for fear of failure refers to negative motivation when a person seeks to avoid censure or punishment. Individuals of this type are low-initiative, avoid responsible tasks, and find reasons for refusing them. They set themselves unjustifiably high goals and assess their capabilities poorly. The questionnaire consisted of 20 questions, assuming an answer according to a dichotomous scale ("yes" or "no"). As a result of processing with the key, the total indicator is calculated, which can have a value of $0-20$ points. Each matches with the key -1 point. If the number of points scored ranged from 1 to 7 , the motivation for fear of failure was diagnosed. If the number of points scored ranged from 14 to 20, the motivation for success was diagnosed. If the number of points scored ranged from 8 to 13, then it should be assumed that the motivational pole was not clearly expressed.

The method of determining the level of critical thinking of the American author $\mathrm{L}$ Starkey (adapted by E. L. Lutsenko) is an objective test that meets the psychometric requirements of reliability and validity. The method is designed for the age group from 16 to 70 years and consists of 27 questionnaire statements, each with four options for choosing the correct answer. Many tasks of the Starkey test are aimed at specific skills or cognitive actions (searching for information, evaluating facts, setting goals), but there are also tasks for general mental operations - logic and analysis. As a result of processing with the key, the total critical thinking score is calculated, which can have a value from 0 to 27 points. The resulting indicator corresponds to a low, medium, or high level of critical thinking. A low level of critical thinking is characterized by insufficient development of logic, a low ability to select unreliable information, collect objective information, make informed decisions, discuss, collect objective information, make informed decisions, and discuss with reasoned arguments. A group of respondents with a high level of critical thinking can identify causal relationships, develop optimal, complex, and responsible decisions in conditions of uncertainty and risk, set realistic goals, and find adequate ways to achieve them. 
Based on a complex methodology, the diagnosis of the primary state of the personal characteristics of spirituality was performed before and after implementing the program. For the convenience of comparative analysis, all diagnostic data were divided into low, medium, and high levels. For visual representation of empirical data and their subsequent analysis, the scores obtained were presented as percentage.

However, qualitative characteristics were also used to confirm the effectiveness of the experimental approach. One of the key characteristics was the activation of teachers' research activities in spiritual and moral education (preparation of scientific articles, development of research projects, and participation in conferences). The next characteristic can be considered students' interest in continuing the program of spiritual and mental development.

\section{Data Analysis}

All variables were analyzed using descriptive statistical methods for mean values and standard deviations. The nonparametric Wilcoxon signed-rank T-test for dependent samples was used to analyze and evaluate the level of formation of personality qualities and abilities that express the development of the spiritual and moral sphere and related components of personal potential.

The original program complex for organizing high-performance calculations "Statistical Criteria of Differences" was developed in the object-oriented programming language $\mathrm{C \#}$ in the integrated development environment Visual Studio was used to evaluate experimental data. This program allowed for the selection of the necessary tool to identify a statistically significant trend in the shift of indicators, particularly nonparametric Wilcoxon T-criteria, and automatically perform quantitative processing of a large volume of data. By filling in the required fields for each participant, the computer program made it possible to automatically carry out quantitative processing of a large amount of data using all criteria. The assessment of the spiritual and moral effects for each listener was carried out according to the following scheme: the total test scores were calculated for each criterion separately before and after the experimental training, distribution by levels according to the applied diagnostic methods, and statistical check using the Wilcoxon signed-rank T-test to identify significant or insignificant differences in all criteria before and after experimental training.

\section{Results}

Table 1 presents the diagnostics results of the dynamics of the development and formation level of the spiritual and moral sphere. These results demonstrate positive dynamics in all components of spiritual and moral spheres. From the first to the second level, 18 people moved from the second to the third (11 people). The total number of students who raised their level of spiritual and moral culture was 21 . The best changes are determined by the value-semantic and reflexive components. However, a slight decrease in motivation at a high level was noted. In this regard, the quantitative assessment of the motivational component contribution to the overall structure of the spiritual and moral components requires a more detailed statistical and qualitative analysis. 


\section{Table 1}

The Results of Diagnostics of Dynamics of Spiritual and Moral Sphere Development Level

\begin{tabular}{|c|c|c|c|c|c|c|}
\hline \multirow{3}{*}{ Components } & \multicolumn{6}{|c|}{ Levels of spiritual and moral development, \% } \\
\hline & \multicolumn{2}{|c|}{ low } & \multicolumn{2}{|c|}{ medium } & \multicolumn{2}{|c|}{ high } \\
\hline & before & after & before & after & before & after \\
\hline \multirow{2}{*}{ Value-semantic } & \multicolumn{2}{|c|}{$110.15-116.95$} & \multicolumn{2}{|c|}{$116.96-123.75$} & \multicolumn{2}{|c|}{$123.76-130.56$} \\
\hline & 50.00 & 37.50 & 37.50 & 37.50 & 12.50 & 25.00 \\
\hline \multirow{2}{*}{ Communicative } & \multicolumn{2}{|c|}{$22-60$} & \multicolumn{2}{|c|}{$61-99$} & \multicolumn{2}{|c|}{$100-132$} \\
\hline & 41.67 & 29.17 & 37.50 & 41.67 & 20.83 & 29.17 \\
\hline \multirow{2}{*}{ Reflexive } & \multicolumn{2}{|c|}{$80-122$} & \multicolumn{2}{|c|}{$123-147$} & \multicolumn{2}{|c|}{ 148-172 } \\
\hline & 66.67 & 41.67 & 20.83 & 33.33 & 12.50 & 25.00 \\
\hline \multirow{2}{*}{ Motivational } & \multicolumn{2}{|c|}{$1-7$} & \multicolumn{2}{|c|}{$8-13$} & \multicolumn{2}{|c|}{$14-20$} \\
\hline & 50.00 & 37.50 & 33.33 & 50.00 & 16.67 & 12.50 \\
\hline \multirow{2}{*}{ Critical } & \multicolumn{2}{|c|}{$<12$} & \multicolumn{2}{|c|}{$12-25$} & \multicolumn{2}{|c|}{$>25$} \\
\hline & 41.67 & 29.17 & 45.83 & 54.17 & 12.50 & 16.17 \\
\hline
\end{tabular}

The graphical presentation of the experimental results demonstrates the effectiveness of the proposed program (Fig. 1). Empirical data are presented as averages and standard deviations for each component before and after the implementation of the training program. The participants showed an increase in the average indicators for all components, and the most significant changes occurred in the communicative and reflexive components.

\section{Figure 1}

Graphical Presentation of the Experimental Results

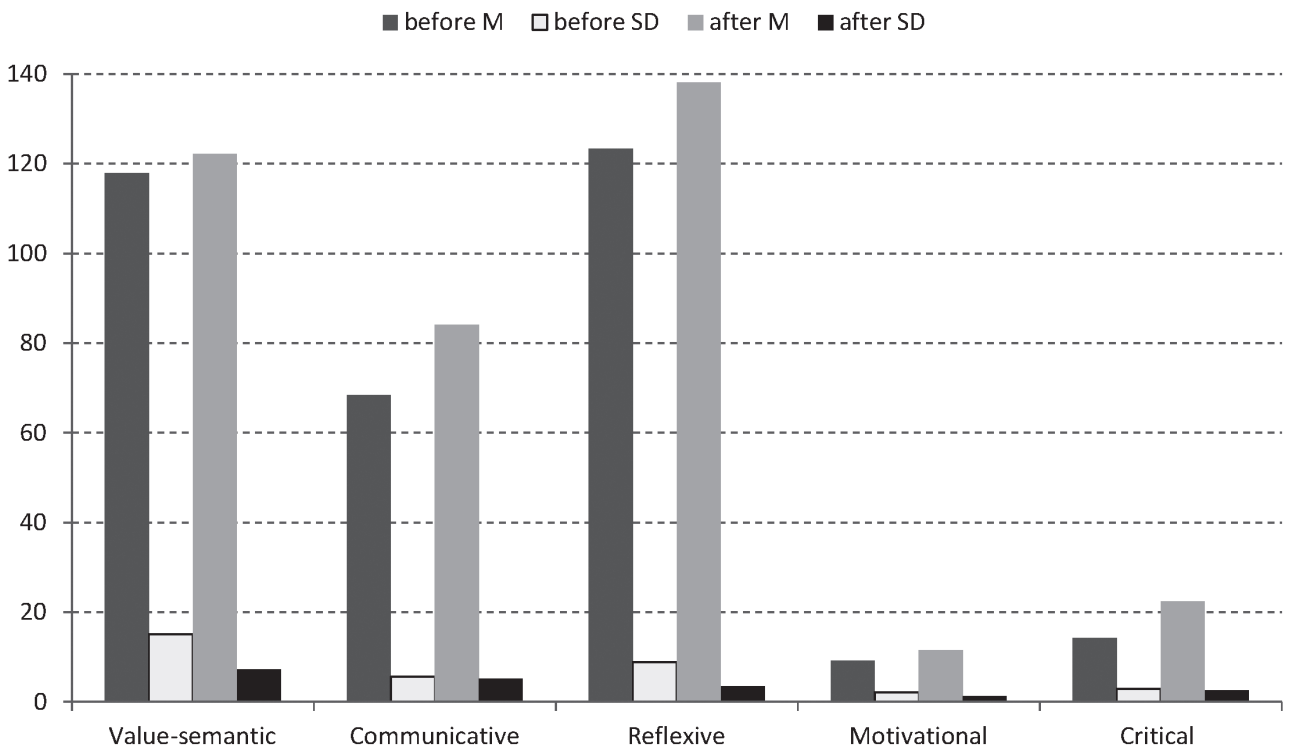


Statistical testing revealed significant changes in all components: value-semantic $(\mathrm{T}=4.5, \mathrm{p}<0.05)$, motivational $(\mathrm{T}=17.5, \mathrm{p}<0.05)$, reflexive $(\mathrm{T}=4, \mathrm{p}<0.05)$, communicative $(\mathrm{Temp}=41.5, \mathrm{p}<0.05)$, and critical $(\mathrm{T}=33.5, \mathrm{p}<0.05)$ components.

The motivational components of spiritual and mental development were confirmed using other indicators. Moreover, almost $50 \%$ of the students who were trained participated in conferences on spiritual and moral education (for example, in the $7^{\text {th }}$ international scientific and practical conference "The Orthodox Christian Scientist in the Modern World”, Kursk, December 12-13, 2018), and published scientific articles in line with this subject area.

More than $60 \%$ of the course participants continued to study spiritual and moral education problems, as reported at conferences on other topics. Example of the reports: "Creating a Media Resource on the History of Mathematics Education as a Means of Spiritual and Moral Education in the Research Activities of Students" ( $2^{\text {nd }}$ international pedagogical forum "Art education for sustainable development of society", Minsk (Belarus), November 12-13, 2019), "Transformation of Mathematics Education in Russia and Moral Education" (SCTCMG 2019 - Social and Cultural Transformations in the Context of Modern Globalism, June 14-15, 2019) (Savvina \& Melnikov, 2019), and others.

Under the guidance of teachers (course participants), students conducted research on moral education. Students took part and won prizes in the 7th international youth competition of scientific works "Moral Imperatives in Law, Education, Science and Culture" (Belgorod 2019).

\section{Discussion}

The research goal was achieved. The results of this study are largely consistent with those of the international studies. In particular, the study found that an additional education program was an effective form of implementing the spiritual and moral formation and development of the teacher's personality. This result is consistent with the previously published data.

Further, the authors theoretically and empirically proved that the integration of mathematical and humanistic knowledge in higher education would have a spiritual and moral effect. Previous studies also confirm this fact (Dvoryadkina et al., 2018; Ptitsyn, 2019; Savvina \& Melnikov, 2019). This research not only established the effective role of mathematics in maths teachers' spiritual and moral formation and development but also expanded the range of didactic tools for the formation of this phenomenon.

Most modern researchers focus on the education of morality and the development of spirituality in children, rather than on adults while using the potential of the humanities (Bahchieva, 2017; Bazarova, 2019; Belkin et al., 2016). The investigated issues of spiritual education are relevant to the background of the general spiritual crisis of modern society, the lack of modern youth life guidelines and meanings (Belkin et al., 2015, 2016; Bazarova, 2019; Shirshov, 2020; Korolkov, 2006; Carpenter, 2020; Deakin \& Jelfs, 2011; Kaili \& Yu, 2012; Menshikov \& Khokhlova, 2018; Tokic \& Nikolic, 2019).

Our study focuses on the development of spiritual and moral values in working teachers by means of mathematics. Thus, it contributes to pedagogical science because it is important to explore spiritual and moral education of both children and adults, particularly teachers, considering their mature age and pedagogical experience. A modern 
teacher who performs his or her professional duties, carries out activities in conditions of socio-political, economic, and socio-cultural instability must possess a high spiritual development level.

The structural components of the spirituality model identified by the authors (meaning of life, awareness of the life goal, axiological competence, general communicative tolerance, self-actualisation, self-evaluation of personality, reflection, criticality, and motivational activity), which are fully consistent with the structural components of the spirituality of most researchers (Belkin et al., 2015, 2016; Bazarova, 2019; Shirshov, 2020; Korolkov, 2006; Menshikov \& Khokhlova, 2018; Carpenter, 2020; Solovtsova, 2012), allowed us to develop a comprehensive diagnostic technique for studying the formation of the content aspects of this phenomenon. Based on this methodology, significant changes were identified in all the diagnosed indicators after the implementation of the program of spiritual and moral development; to the greatest extent, the changes affected the communicative and reflexive components of the concept of spirituality. This fact can be explained by the mature age of the program participants and extensive professional experience, which is also confirmed by modern research (Bayeva, 2015; Pandya, 2020).

In this study, the authors limited themselves to the following aspects:

- The sample comprises only Russian teachers and it was small.

- The effectiveness of the proposed program for spiritual and mental development was assessed based on one experimental sample. Therefore, the results obtained require confirmation when organizing a study using control and experimental samples.

- When developing a toolkit for identifying and assessing the spiritual and moral effects, the authors identified and used only its main characteristics without considering secondary factors.

- It is necessary to examine the presented diagnostic tools of spirituality for validity and reliability, and establish a correlation between the selected components of the spiritual and moral sphere.

The following research areas are possible in the future:

Our program can be applied universally. Therefore, we recommend using it for the development of advanced training programs for educators in both humanities and sciences. It is necessary to make additional changes in the age composition of participants (consider both experienced teachers with many years of teaching practice and young teachers).

\section{Conclusions}

Despite the different geographical, cultural and political conditions in which the educational systems of different countries exist, it is possible to distinguish common ideas about spiritual and moral values, the formation of which can be ensured through the teaching of mathematics as a universal scientific language. The peculiarity of the research is to ensure the continuity of the process of forming spiritual values in the modern conditions of openness of the information environment, in the environment of competition of worldviews, views on key moral problems. Therefore, the solution to the problems of spiritual and moral education should prevail in the programs of advanced training of mathematics teachers, especially for teachers of mathematics. As criteria for the manifestation of spiritual and moral effects of experienced teachers, it is proposed 
to consider the interest in scientific education and the desire for self-improvement. The implementation of scientific and practical results in the educational process within the framework of professional development programs for educators contributes to the formation of the worldview and spiritual and moral qualities of the professional personality.

\section{References}

Bahchieva, O. A. (2017). Integrative opportunities of local history within spiritual and moral education of teacher. International Conference on Research Paradigms Transformation in Social Sciences, 2357-1330. doi: 10.15405/epsbs.2018.02.12

Bayeva, L. V. (2015). Quality of life and human values. Bulletin of Volgograd State University, 3(29), 108-14.

Bazarova, U. (2019). The role of spiritual and moral education of students of technical university in the lessons of foreign languages. Theoretical \& Applied Science, 11(79), 614-616. doi: 10.15863/TAS.2019.11.79.123

Belkin, A. I., \& Tropina, L. P. (2015). Spiritual education in a Russian University on the example of the study of St. Sergius of Radonezh Asceticism. Integration of Education, 3(19), 122-130. doi: 10.15507/Inted.080.019.201503.122

Benson, P. L. (2004). Emerging themes in research on adolescent spiritual and religious development. Applied Developmental Science, 8(1), 47-50. doi: 10.1207/s1532480 xads0801_6

Bigger, S. (2013). Spiritual, Moral, Social, \& Cultural Education. London: Routledge. doi: $10.4324 / 9781315068428$

Buyeva, L. P. (2005). Spirituality and problems of moral culture. Problems of Philosophy, $2,28$.

Carpenter, W. (2020). The limits and direction of character education: Issues moral and spiritual. Religion \& Education, 27(1), 65-71. doi: 10.1080/15507394.2000. 11000918

Carr, D. (1995). Towards a distinctive conception of spiritual education. Oxford Review of Education, 21(1), 83-98.

Carr, D. (1996). Rival conceptions of spirituality. Journal of Philosophy of Education, 30(2), 159-178.

Chiang, Y. Ch., Lee, H. Ch., Chu, T. L., Chin-Yen Han, Ch. Y., \& Hsiao, Y. Ch. (2020). A spiritual education course to enhance nursing students' spiritual competencies. Nurse Education in Practice, 49, 102907. doi: 10.1016/j.nepr.2020.102907

Croce, M. (2019). Exemplarism in moral education: Problems with applicability and indoctrination. Journal of Moral Education, 48(3), 291-302. doi: 10.1080/ 03057240.2019 .1579086

Curren, R. (2014). Motivational aspects of moral learning and progress. Journal of Moral Education, 43(4), 484-499. doi: 10.21603/2542-1840-2019-3-2-119-125

Deakin, C. R., \& Jelfs, H. (2011). Spirituality, learning, and personalization: Exploring the relationship between spiritual development and learning to learn in a faithbased secondary school. International Journal of Children's Spirituality, 16(3), 197-217. doi: 10.1080/1364436x.2011.613068

Dvoryatkina, S. N., Mkrtchyan, M. A., \& Rozanova, S. A. (2018). Spiritual and moral effect as a result of integration of mathematical and humanistic knowledge in higher school. Integration of Education, 22(2), 355-70. 
Federal State Educational Standard of Higher Education. (2018). http://fgosvo.ru/ uploadfiles/FGOS\%20VO\%203++/Bak/440305_B_3_16032018.pdf

Halstead, J. M. (1994). Moral and spiritual education in Russia. Cambridge Journal of Education, 24(3), 423-438. doi: 10.1080/0305764940240309

Kaili, C. Z., \& Yu, E. D. (2012). Quest for a good life: Spiritual values, life goals, and college students. Journal Asia-Pacific Psychiatry, 6(1), 91-98. doi: 10.1111/j.17585872.2012.00183.x

Khagurov, T. A., \& Ostapenko, A. A. (2011). What do we have to lose by turning education into training and service? Educational Technology, 4, 26-29.

Khugaeva, F. (2019). Modern forms of spiritual and moral education of students in multi-cultural environment. Baltic Humanitarian Journal, 8(1, 26), 308-312. doi: 10.26140/bgz3-2019-0801-0080

Korolkov, A. A. (2006). Spiritual meaning of Russian culture. Publishing House of the A. I. Herzen RSPU.

McLaughlin, T. H. (2003). Education, spirituality and the common school. In D. Carr, \& J. Haldane (Eds.), Philosophy, spirituality and education. Routledge.

Menshikov, V. M., \& Khokhlova, A. B. (2018). About requirements to professional training of the teacher called for spiritual and moral education (on the material of works of K. D. Ushinsky and Theophan the Recluse). Scientific bulletins of Belgorod State University, 37(2), 329-35. doi: 10.18413/2075-4574-2018-37-2329-335

Moghaddam, E. Z., Vashani, H. B., Reihani, T., \& Zadegan, S. N. (2016). The effect of spiritual education on depression, anxiety and stress of caregivers of children with leukemia. Journal of Tanin Salamat (Health Chimes), 4(1), 1-7.

Moulin-Stożek, D. (2020). Spiritual development as an educational goal. ECNU Review of Education, 3(3), 504-518. doi: 10.1177/2096531120935128

Nalyotova, I. V. (1999). Spirituality as a socio-cultural phenomenon. TSU Bulletin, $1(13), 71-76$.

Pandya, S. (2020). Teaching spiritual techniques in continuing education programs to train older adults for community service and volunteer work contributes to selfefficacy and prosocial behaviors: A five-year follow-up study in four South Asian cities. Journal of Adult and Continuing Education, 26(1), 73-96. doi: 10.1177/ 1477971419869359

Ptitsyn, V. A. (2019). Computer modeling of folk patterns as a tool for studying the theme "Modeling" and spiritual education of students. Informatics in School, 6, 30-36. doi: 10.32517/2221-1993-2019-18-6-30-3

Rean, A. A. (2006). Psychology and psychodiagnostics of personality. Theory, research methods, workshop. Prime-Evroznak.

Rodger, A. (2000). The spiritual in values education. Journal of Moral Education, 29(4), 463-475. doi: 10.1080/713679389

Rossiter, G. (2006). The moral and spiritual dimension to education: Some reflections on the British experience. Journal of Moral Education, 25(2), 201-214. doi: 10.1080/ 0305724960250205

Sample discipline program “History”. http://fgosvo.ru/uploadfiles/ppd/2011032900 1204.pdf

Sample program "Philosophy”. http://fgosvo.ru/uploadfiles/ppd/20110329000 946.pdf 
Sardoč, M. (2019). Making sense of moral education: Guest editor's preface to a book symposium on a theory of moral education by Michael Hand. Journal of Moral Education, 48(4), 499-500. doi: 10.1080/03057240.2019.1660629 2019

Savvina, O. A., \& Melnikov, R. A. (2019). Transformation of mathematical education in Russia and moral education (SCTCMG 2019 - Social and Cultural Transformations in the Context of Modern Globalism. Vol. LXXVI, 28 December 2019). In The European proceedings of social \& behavioral sciences EpSBS. doi: 10.15405/ epsbs.2019.12.04.377

Shirshov, V. (2020). Moral and spiritual education. Infra-M. doi: 10.12737/996096

Slobodchikov, V. I. (2010). Spiritual problems of man in the modern world. Social Pedagogy, 4, 87-94.

Solovtsova, I. A. (2012). Values as the basis for goal-setting in the field of spiritual and moral education. Frontiers of Knowledge, 3(17), 91-94.

Starkey, L. (2004). Critical thinking skills success in 20 minutes a day. Learning Express, LLC.

Szutta, N. (2019). Exemplarist moral theory - Some pros and cons. Journal of Moral Education, 48(3), 280-290. doi: 10.1080/03057240.2019.1589435

Tisdale, T. C. (2014). Psychology and spiritual formation: The state of the union. Journal of Spiritual Formation \& Soul Care, 7(2), 220-228. doi: 10.1177/193979091400 700206

Tokic, A., \& Nikolic, M. (2019). Moral reasoning among Croatian students of different academic orientation. European Journal of Multidisciplinary Studies, 6(2), 208213. doi: 10.26417/ejms.v6i2.p

Troitsky, V. P. (2010). The fate of the Russian school. Moscow: Institute of Russian Civilisation.

Valiakhmetov, Kh., \& Abolin, L. M. (2002). Culture and art in the structure of event activity of development of spiritual and moral personality. Professional Education, 4, 10-18.

Watson, L. (2019). Educating for inquisitiveness: A case against exemplarism for intellectual character education. Journal of Moral Education, 48(3), 303-315. doi: 10.1080/03057240.2019.1589436

Wilson, K. (1993). Moral and spiritual education. Westminster Studies in Education, 16(1), 5-7. doi: 10.1080/0140672930160102

Wintersgill, B. (2008). Teenagers' perceptions of spirituality - A research report. International Journal of Children's Spirituality, 13(4), 371-378. doi: 10.1080/ 13644360802439565

Correspondence concerning this article should be addressed to Sergey Shcherbatykh, Doctor of Education, Professor, Vice-Rector for Academic Affairs, Bunin Yelets State University, Yelets, Russian Federation. Email: Scherbatych2017@yandex.ru 